\title{
Knockdown of integrin $\alpha 3 \beta 1$ expression induces proliferation and migration of non-small cell lung cancer cells
}

\author{
HYUN JAE YOON ${ }^{1}$, YOUNG-RAK CHO $^{2}$, JI-HYE JOO ${ }^{2}$ and DONG-WAN SEO ${ }^{2}$ \\ ${ }^{1}$ Quality Management Department, Hugel Inc., Chuncheon 200-821; \\ ${ }^{2}$ College of Pharmacy, Dankook University, Cheonan 330-714, Republic of Korea
}

Received August 21, 2012; Accepted October 22, 2012

DOI: $10.3892 /$ or.2012.2169

\begin{abstract}
Integrin $\alpha 3 \beta 1$ is expressed on many types of cancer cells and can regulate tumor growth and progression. In the present study, we examined the roles and molecular mechanism of integrin $\alpha 3 \beta 1$ in modulating cell proliferation and migration of p53-deficient non-small cell lung cancer (NSCLC) cells. Reduced expression of integrin $\alpha 3$ by RNA silencing clearly induces cell proliferation and migration in H1299 cells, compared with those in control cells. Enhanced proliferation in integrin $\alpha 3$-silenced cells is mediated by upregulation and nuclear localization of cyclin-dependent kinases, and these effects require the activation of Akt and ERK as evidenced by treatment with LY294002 and PD98059, respectively. Furthermore, suppression of integrin $\alpha 3$ expression induces the expression of nuclear factor- $\kappa \mathrm{B}$ and $\mathrm{Bcl}-2$ as well as epidermal growth factor receptor, which are positively correlated with cell proliferation and survival. In contrast, increase in cell migration of integrin $\alpha 3$-silenced cells is found to be independent of Akt or ERK signaling pathways. Collectively, these findings suggest that integrin $\alpha 3 \beta 1$ plays pivotal roles in regulating cell proliferation and migration that enhance the invasive type of p53-deficient NSCLC cells.
\end{abstract}

\section{Introduction}

Integrins, cell surface receptors that mediate cell-extracellular matrix (ECM) and cell-cell interactions, function to modulate cell behaviors including cell adhesion, migration, proliferation, survival, invasion and angiogenesis (1-3). Integrin-mediated signaling cascades include the activation of a variety of protein kinases such as focal adhesion kinase, Src-family kinases, extracellular signal-regulated kinase (ERK), and phosphatidylinositol

Correspondence to: DrDong-Wan Seo,Laboratory of Biochemistry, Department of Pharmacy, College of Pharmacy, Dankook University, Pharmacy Hall, 119 Dandae-ro, Room 319, Cheonan 330-714, Republic of Korea

E-mail: dwseomb@dankook.ac.kr

Key words: integrin $\alpha 3 \beta 1, \mathrm{p} 53, \mathrm{EGFR}, \mathrm{NF}-\kappa \mathrm{B}$, lung cancer 3-kinase (PI3K)/Akt $(1,3)$. These signaling events are complex and very similar to those triggered by growth factor receptors, demonstrating cross-talk between ECM- and growth factorinduced signal transduction pathways, which are involved in physiological and pathological processes (3-5). Integrin $\alpha 3 \beta 1$, a major receptor for laminin, is expressed on many types of cancer cells and plays the pivotal roles in regulation of cancer progression $(3,6)$. Reduced integrin $\alpha 3$ expression in lung cancer is probably associated with increased aggressiveness and poor prognosis in lung cancer patients $(7,8)$. Although significant advances have been made in understanding the function of integrin $\alpha 3 \beta 1$, the roles and molecular mechanisms in mediating the regulation of malignant cell behavior still remain unexplored.

The epidermal growth factor receptor (EGFR) is a receptor tyrosine kinase which is highly expressed or activated in a variety of human cancers including lung, ovary, stomach, brain, breast and colon cancer, and it has therefore been known as the main therapeutic target for cancer treatment (9-11). EGFRdependent signaling pathways include the activation of Akt and ERK, which are implicated in the cell proliferation, survival, migration and invasion (9). In addition, recent studies have established that nuclear factor- $\kappa \mathrm{B}(\mathrm{NF}-\kappa \mathrm{B})$ is closely associated with regulation of cell proliferation and anti-apoptosis as well as inflammation and immune responses $(12,13)$. NF- $\kappa \mathrm{B}$ activation can either promote or suppress the proliferation and survival of cancer cells, depending on the cell and tissue types as well as the expression status of tumor suppressor proteins such as p53 or phosphatase and tensin homolog (12).

In the present study, we evaluated the biological effects and molecular mechanisms of integrin $\alpha 3 \beta 1$ on cell proliferation and migration in p53-deficient human lung cancer H1299 cells. Enhanced proliferation and migration in integrin $\alpha 3$-silenced cells are mediated by activation of Akt and ERK-dependent pathways and induction of cyclin-dependent kinases, EGFR, and $\mathrm{NF}-\kappa \mathrm{B}$-inducible anti-apoptotic protein Bcl-2. These findings indicate that reduced integrin $\alpha 3$ expression in p53-deficient NSCLC cells results in multiple phenotypic changes that enhance the aggressiveness.

\section{Materials and methods}

Cell culture conditions. Human lung carcinoma cells (H1299) from American Type Culture Collection (Manassas, VA, USA) 
were grown in $10 \%$ fetal bovine serum-Dulbecco's modified Eagle's medium (FBS-DMEM) (HyClone Laboratories, Logan, UT, USA).

Reagents. PD98059 (MEK 1/2 inhibitor) and LY294002 (PI3K inhibitor) were obtained from Upstate Biotechnology (Lake Placid, NY, USA). The following antibodies were purchased from commercial sources: anti-phospho-ERK (T202/Y204), anti-phospho-Akt (Ser473), anti-lamin A/C (Cell Signaling, Beverly, MA, USA); anti-integrin $\beta 1$ (BD Biosciences, Bedford, MA, USA); anti-integrin $\alpha 3$, anti-EGFR, anti-ERK, anti-Akt, anti-Cdk4, anti-Cdk2, anti-p27 ${ }^{\mathrm{Kipl}}$, anti-NF-KB, anti-Bcl-2, antiactin antibodies, and mouse, rabbit and goat IgG-horseradish peroxidase conjugates (Santa Cruz Biotechnology, Santa Cruz, CA, USA).

$R N A$ purification and RT-PCR. Total RNA was purified with easy Blue ${ }^{\mathrm{TM}}$ Total RNA extraction kit (iNtRON Biotechnology, Sungnam, Gyeonggi, Korea). Integrity of RNA was checked by agarose gel electrophoresis and ethidium bromide staining. RNA $(1 \mu \mathrm{g})$ was used as template for each reverse-transcriptase (RT)-mediated polymerase chain reaction (PCR) by using the ImProm-II ${ }^{\mathrm{TM}}$ Reverse Transcription System (Promega, Madison, WI). Primers for PCR were synthesized by Bioneer Corporation (Daejeon, Korea). Primer sequences were: integrin $\alpha 3$, forward 5'-AAGCCAAGTCTGAGACT-3' and reverse 5'-GTAGTATTGGTCCCGAGTCT-3'; glyceraldehyde3-phosphate dehydrogenase (GAPDH), forward 5'-GAA GGTGAAGGTCGGAGTC-3' and reverse 5'-GAAGATGGT GATGGGATTTC-3' (14).

siRNA preparation and transfection. For design of siRNA inserts, a cDNA sequence of integrin $\alpha 3$ AGCAACACAGAC TACCTGGAG was selected according to the InvivoGen siRNAWizard program based on a BLAST search. As a control we used the scrambled oligonucleotide sequence AGCATA TGTGCGTACCTAGCT, available prepackaged in the psiRNAhH1zeo vector (InvivoGen, San Diego, CA, USA). Both the siRNA-targeting integrin $\alpha 3$ gene and scrambled sequences cloned into psiRNA-hH1zeo vector were designated $\alpha 3$ shRNA and control shRNA, respectively. These vector constructs were transfected into H1299 cells using LyoVec (InvivoGen) according to the manufacturer's instructions. After $48 \mathrm{~h}$, the cells were selected with zeocin in 10\% FBS-DMEM for 1-2 weeks until positive colonies formed (15).

Adhesion assay. Subconfluent cells were detached with trypsin and allowed to recover in 10\% FBS-DMEM for $1 \mathrm{~h}$ at $37^{\circ} \mathrm{C}$ with gentle rocking. After recovery, the cells were collected by low-speed centrifugation and resuspended in fresh $10 \%$ FBS-DMEM. The cells were plated on non-coated, laminincoated, or collagen-coated 96 -well plates $\left(1.5 \times 10^{4}\right.$ cells/well), and further incubated for $2 \mathrm{~h}$ at $37^{\circ} \mathrm{C}$. Following incubation unattached cells were removed by washing the wells three times with ice-cold phosphate buffered saline (PBS, pH 7.4). Attached cells were fixed with methanol, and then stained with $0.04 \%$ Giemsa staining solution (Sigma-Aldrich Co., St. Louis, MO, USA). The cells were photographed and counted. The results (mean \pm standard deviation) are presented as the fold-increase of the untreated adherent cells (16).
Cell growth assay. Subconfluent control shRNA or integrin a3 shRNA-transfected H1299 cells, plated on 6-well plates ( $2 \times 10^{4}$ cells/well), were serum-starved for $48 \mathrm{~h}$ to synchronize cells in $\mathrm{G}_{1} / \mathrm{G}_{0}$ phase of cell cycle, and further incubated with $10 \%$ FBS-DMEM for the indicated time points in the presence or absence of MEK or PI3K inhibitor. The cells were then washed in ice-cold PBS, detached with trypsin, and counted using trypan blue exclusion method. The results from triplicate determinations (mean \pm standard deviation) are presented as the numbers of cells per culture or the fold-increase of the untreated controls.

Migration assay. Cell migration was quantified in the in vitro wound-healing assay as previously described (17). After cells were plated on 48-well plates, grown to confluence, and a single wound was created in the center of the cell monolayer by the gentle removal of the attached cells with a sterile plastic pipette tip. Cells were pretreated with or without MEK or PI3K inhibitor for $30 \mathrm{~min}$, followed by serum stimulation for $18 \mathrm{~h}$. Cells were fixed with methanol, and then stained with $0.04 \%$ Giemsa staining solution. The migration of the cells into the wound was observed with still images taken at the indicated time point.

Western blot analysis. Subconfluent cells in 100-mm dishes (BD Biosciences) were serum-starved for $48 \mathrm{~h}$ in DMEM and replaced with fresh media, followed by treatments for different time points, as indicated. Cells were rinsed twice with ice-cold PBS and lysed by incubation in $50 \mathrm{mM}$ Tris- $\mathrm{HCl}$ (pH 7.4), $150 \mathrm{mM} \mathrm{NaCl}, 10 \%$ glycerol, $1 \%$ Triton X-100, 1 mM EDTA, $100 \mu \mathrm{g} / \mathrm{ml}$ 4-(2-aminoethyl)benzenesulfonyl fluoride, $10 \mu \mathrm{g} / \mathrm{ml}$ aprotinin, $1 \mu \mathrm{g} / \mathrm{ml}$ pepstatin A, $0.5 \mu \mathrm{g} / \mathrm{ml}$ leupeptin, $80 \mathrm{mM}$ $\beta$-glycerophosphate, $25 \mathrm{mM} \mathrm{NaF}$ and $1 \mathrm{mM}$ sodium orthovanadate for $30 \mathrm{~min}$ at $4^{\circ} \mathrm{C}$. Cell lysates were clarified at $13,000 \mathrm{x} \mathrm{g}$ for $20 \mathrm{~min}$ at $4^{\circ} \mathrm{C}$, and the supernatants were subjected to western blot analysis as described previously (18).

Subcellular fractionation. Following treatments as indicated, cells were rinsed twice with ice-cold PBS, and cytoplasmic and nuclear extracts were prepared using Nuclear/Cytosol Fractionation kit (BioVision Inc., Mountain View, CA, USA), according to the manufacturer's instructions.

Zymogram analysis. Activities of matrix metalloproteinases were measured by zymography (19). Aliquots of conditioned medium were diluted in sample buffer, applied to $10 \%$ polyacrylamide gels containing $1 \mathrm{mg} / \mathrm{ml}$ gelatin (SigmaAldrich Co.) as a substrate. After electrophoresis, the gels were incubated in $2.5 \%$ Triton X-100 for $1 \mathrm{~h}$ to remove SDS and allow re-naturalization of MMPs, and further incubated in developing buffer containing $50 \mathrm{mM}$ Tris- $\mathrm{HCl}(\mathrm{pH} 7.5)$, $10 \mathrm{mM} \mathrm{CaCl}_{2}$, and $150 \mathrm{mM} \mathrm{NaCl}$ for $20 \mathrm{~h}$ at $37^{\circ} \mathrm{C}$. The gels were stained with $0.5 \%$ Coomassie brilliant blue R-250 in $30 \%$ methanol-10\% acetic acid for $2 \mathrm{~h}$ and followed by destaining with $30 \%$ methanol-10\% acetic acid. Gelatinolytic activities were detected as unstained bands against the background of the Coomassie blue-stained gelatin.

Statistical analysis. Statistical analysis was performed using Student's t-test, and was based on at least three different 
$\mathbf{A}$

B
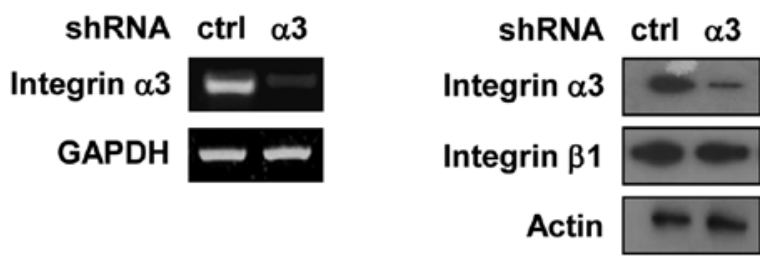

C

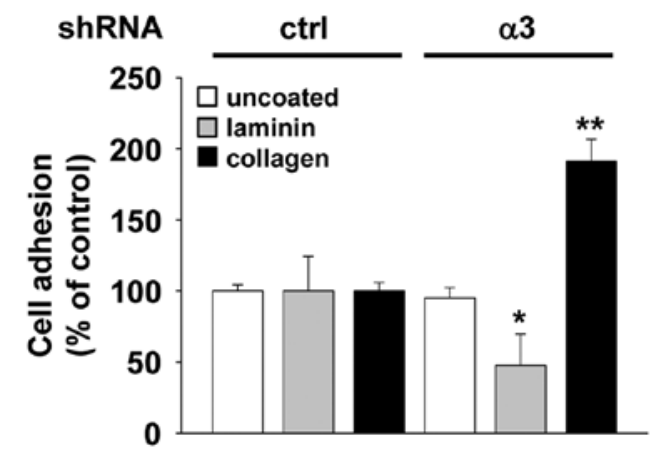

Figure 1. Adhesive behavior of integrin $\alpha 3$-silenced H1299 cells on ECM proteins. The levels of integrin $\alpha 3$ and $\beta 1$ in $\mathrm{H} 1299$ cells were determined by RT-PCR (A) and western blot analysis (B) as described in Materials and methods. Expression of glyceraldehyde-3-phosphate dehydrogenase (GAPDH) and actin was used as internal control. Results shown are representative of at least three independent experiments. (C) Cells $\left(1.5 \times 10^{4}\right.$ cells/well $)$ were plated on 96-well plates either uncoated or coated with proteins including laminin and collagen. The number of attached cells was determined by counting 10 random fields of cells (x100 field). Complete (100\%) attachment of control cells to uncoated, laminin, and collagen type I was $264 \pm 11,84 \pm 20$, and $364 \pm 21$, respectively. Cell adhesion results from six independent experiments (mean $\pm \mathrm{SD}$ ) are presented as the fold-increase of control shRNA-transfected cells. Statistical significance is indicated $\left({ }^{*} \mathrm{p}<0.05,{ }^{* *} \mathrm{p}<0.01\right.$, compared with control cells).

experiments. The results were considered to be statistically significant at $\mathrm{p}<0.05$.

\section{Results}

Integrin $\alpha 3$ silencing-induced cell proliferation is mediated by enhanced expression and nuclear localization of cyclindependent kinases. It has been reported that integrin $\alpha 3 \beta 1$ plays the pivotal roles in cell growth and migration $(3,6)$. To investigate the biological roles of integrin $\alpha 3 \beta 1$ in p53-deficient NSCLC, H1299 cells were transfected with psiRNA-hH1zeo vector including siRNA-targeting integrin $\alpha 3$ or scrambled sequences $(15,18)$, and the cells were designated $\alpha 3$ shRNA and control shRNA, respectively. RT-PCR and western blot analysis demonstrated that $\alpha 3$ shRNA dramatically suppressed expression of integrin $\alpha 3$ subunit in H1299 cells when compared with control cells transfected with control shRNA, and did not affect $\beta 1$ subunit expression (Fig. 1A and B). Integrin $\alpha 3 \beta 1$ is abundantly expressed on the epithelial cell membranes and is known to be a major receptor for laminin-5 (3). To test whether integrin $\alpha 3$ functions to regulate the degree of cell adhesion, we first examined the adhesion of integrin $\alpha 3$-silenced H1299 cells to extracellular matrix proteins. As expected, reduction in
A

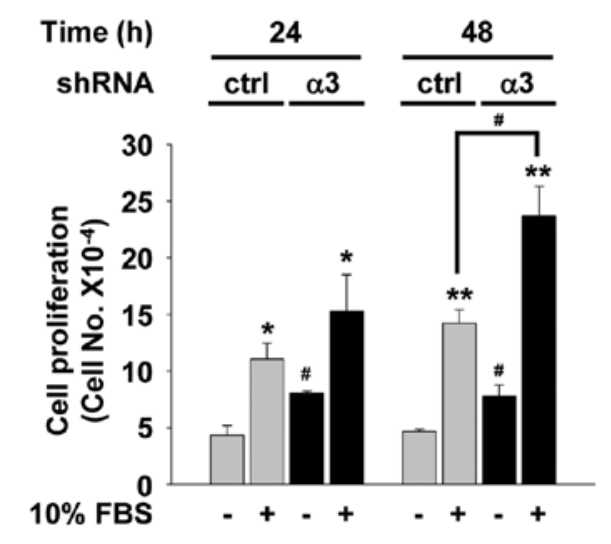

B

ShRNA

ctrl

$\alpha 3$

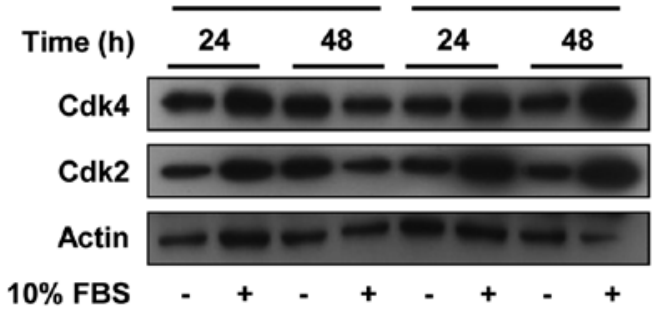

C

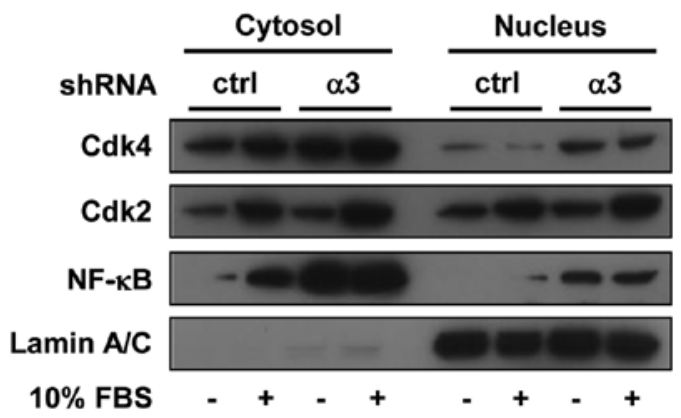

Figure 2. Integrin $\alpha 3$ silencing induces cell proliferation by upregulation and nuclear localization of Cdks and NF-kB. (A) Quiescent cells were treated with or without $10 \%$ serum for the indicated time points. Values represent the mean $\pm \mathrm{SD}$ of three independent experiments. Statistical significance is indicated ( $\mathrm{p}<0.05,{ }^{* *} \mathrm{p}<0.01$, compared with unstimulated cells; ${ }^{*} \mathrm{p}<0.05$, compared with control shRNA-transfected cells). (B) Cell lysates were western-blotted with anti-Cdk4, anti-Cdk2, or anti-actin antibodies. Results shown are representative of at least three independent experiments. (C) Quiescent cells were stimulated with or without $10 \%$ serum for $24 \mathrm{~h}$. The cells were subjected to subcellular fractionation into nuclear and cytosolic extracts as described in Materials and methods. The extracts were western-blotted with anti-Cdk4, anti-Cdk2, anti-NF-kB, or anti-lamin A/C antibodies. Lamin $\mathrm{A} / \mathrm{C}$ was used as a marker for the nucleus. Results shown are representative of three independent experiments.

integrin $\alpha 3$ subunit expression markedly blocked the adhesion of cells to laminin, while did not alter the adhesion to tissue culture plastic (Fig. 1C). In contrast, integrin $\alpha 3$ silencing resulted in a two-fold increase in cell adhesion to collagen when compared with control shRNA (Fig. 1C), consistent with previous reports demonstrating that collagen receptors are 
A

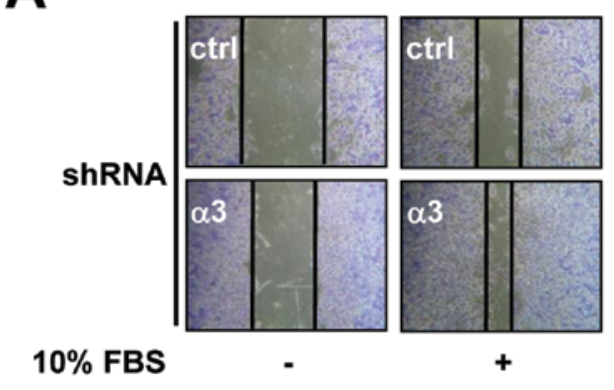

B

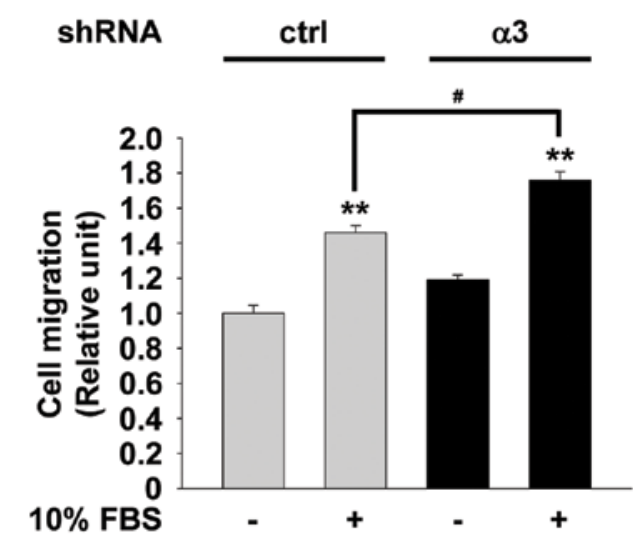

C

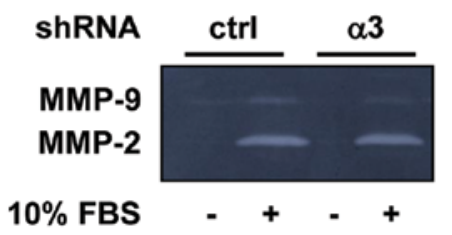

Figure 3. Enhanced migration in integrin $\alpha 3$-silenced cells does not require MMP activity. (A and B) Cell migration was quantified by measuring the migration distance of cells from wound edge as described in Materials and methods. Results from six independent experiments (mean \pm SD) were represented as the fold-increase of unstimulated control shRNA-transfected cells. Statistical significance is indicated $\left({ }^{* *} \mathrm{p}<0.01\right.$, compared with unstimulated cells; ${ }^{\#} \mathrm{p}<0.05$, compared with control shRNA-transfected cells). (C) Gelatin zymogram analysis was carried out by use of conditioned media from control and integrin $\alpha 3$-silenced cells. Zymogram gel loading was normalized to total protein concentration. Results are representative of three independent experiments.

more active in integrin $\alpha 3$-deficient mice keratinocytes (20). In addition, microscopic analysis revealed that integrin $\alpha 3$ silencing did not affect morphological changes in H1299 cells (data not shown).

We next examined the effect and molecular mechanisms of integrin $\alpha 3$ silencing on cell proliferation. Control or integrin $\alpha 3$-silenced H1299 cells were serum-starved for $48 \mathrm{~h}$ to allow synchronization and growth arrest (G1/G0), and then stimulated with 10\% FBS-DMEM for 24 or $48 \mathrm{~h}$. After mitogenic stimulation for $48 \mathrm{~h}$, integrin $\alpha 3$ silencing resulted in a significant increase $(>70 \%)$ in cell proliferation, as compared with controls (Fig. 2A). Of note, integrin $\alpha 3$ silencing also induced cell proliferation in the absence of mitogenic stimuli. After serum starvation for $48 \mathrm{~h}$ this increase was maintained for additional $48 \mathrm{~h}$ culture. These findings suggest that disruption of integrin $\alpha 3$ expression results in induction of cell proliferation and survival, enhancing the aggressiveness of lung cancer and leading to shorter survival of lung cancer patients $(8,21)$. Based on these findings, we next analyzed the changes of cell cycle-related proteins in $\mathrm{H} 1299$ cells. It has been reported that cell cycle progression specifically requires activation of cyclin-dependent kinases (Cdks) through formation with cyclins, and is associated with subcellular localization of Cdks from the cytoplasm to nucleus (22). In control shRNAtransfected cells, mitogenic stimulation increased the protein levels of both Cdk4 and Cdk2 for $24 \mathrm{~h}$, while showed little or no change of protein expression under $48 \mathrm{~h}$ cell culture conditions, compared with those in unstimulated controls (Fig. 2B). However, integrin $\alpha 3$ silencing dramatically induced the levels of Cdks until the end time point of this experiment. The levels of total Cdks in integrin $\alpha 3$-silenced cells were higher than those in control shRNA-transfected cells. These results are consistent with initial findings that integrin $\alpha 3$ silencing functions to increase cell proliferation (Fig. 2A). To investigate whether integrin $\alpha 3$ silencing mediates induction of cell proliferation through the changes of Cdk localization, Cdks in the nuclear compartments were directly examined by western blot analysis of nuclear and cytosolic extracts of H1299 cells with or without integrin $\alpha 3$ shRNA. As shown in Fig. 2C, reduction in integrin $\alpha 3$ expression markedly enhanced nuclear localization of Cdk4, regardless of mitogenic stimulation. Furthermore, $\mathrm{p} 21^{\mathrm{WAF} 1 / \mathrm{Cip} 1}$, one of the best known Cdk inhibitors, was not detected in the nuclear compartments of integrin $\alpha 3$-silenced cells without mitogenic stimulation (data not shown). These changes of Cdk4 and $\mathrm{p} 21^{\mathrm{WAF} 1 / \mathrm{Cip} 1}$ in the nuclear compartments of integrin $\alpha 3$-silenced cells are well correlated with previous observations on cell proliferation (Fig. 2A).

$\mathrm{NF}-\mathrm{\kappa B}$ is well known as a transcription factor that regulates the expression of a variety of genes in response to inflammation, adhesion, cell cycle progression, survival, and anti-apoptosis $(12,13,23)$. Reduced expression of integrin $\alpha 3$ markedly induced the levels of NF- $\mathrm{kB}$ in the cytosolic compartments in both unstimulated and stimulated culture conditions (Fig. 2C). Moreover, nuclear localization patterns of NF- $\kappa \mathrm{B}$ by integrin $\alpha 3$ silencing were similar to those of Cdk4. Collectively, these results demonstrate that knockdown of integrin $\alpha 3$ expression induces cell cycle progression and survival through enhanced expression and nuclear localization of Cdks and NF- $\mathrm{kB}$.

Knockdown of integrin $\alpha 3$ enhances cell migration. Cell migration is controlled by the coordination of integrin-mediated interactions from the ECM to the intracellular components of the migrating cells, and plays the important roles in tumor invasion and metastasis $(1,2,5)$. To study the effect of integrin $\alpha 3$ expression on cell migration, we next performed woundhealing assay using H1299 cells transfected with control or integrin $\alpha 3$ shRNA. As shown in Fig. $3 \mathrm{~A}$ and B, integrin $\alpha 3$-silenced cells readily migrated into the wounded area within $18 \mathrm{~h}$, consistent with previous reports (20). Expression and activation of matrix metalloproteinases (MMPs) are associated with enhanced cell migration and invasion by selective proteolysis of extracellular matrix components (24). Based on integrin $\alpha 3$ silencing-mediated induction of cell migration, we 
A

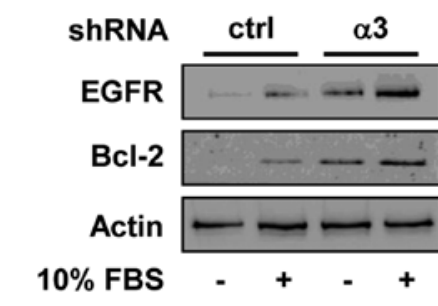

B

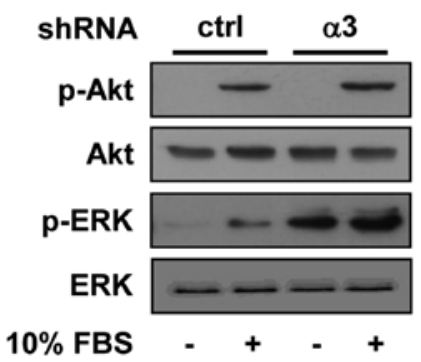

Figure 4. Changes of EGFR expression and signaling pathways in integrin $\alpha 3$-silenced cells. (A and B) Quiescent cells were stimulated with or without $10 \%$ serum for $24 \mathrm{~h}$. Cell lysates were western-blotted with anti-EGFR, anti-Bcl-2, anti-actin, anti-phospho-Akt, anti-Akt, anti-phospho-ERK, or anti-ERK antibodies. Results shown are representative of three independent experiments.

next analyzed the activities of MMP-2 and MMP-9 in H1299 cells. As shown in Fig. 3C, the conditioned media from cell cultures had high levels of MMP-2 activity relative to those of MMP-9. Knockdown of integrin $\alpha 3$ expression significantly reduced MMP-9 activity, but not MMP-2, similar to previous reports that integrin $\alpha 3 \beta 1$ expression is required for the production of MMP-9 in immortalized mouse keratinocytes (25). These observations suggest that integrin $\alpha 3$ silencingmediated induction of H1299 cell migration may not require the expression and activity of MMPs.

Roles of ERK and Akt activation in integrin $\alpha 3$ silencinginduced cell proliferation and migration. To further investigate the molecular mechanism by which knockdown of integrin $\alpha 3$ expression induces cell proliferation and migration, we analyzed the changes in the expression of EGFR, which is overexpressed or constitutively activated in a variety of human cancers including lung cancer (9-11). As shown in Fig. 4A, the expression of EGFR was induced in integrin $\alpha 3$-silenced H1299 cells, as compared with control cells. Moreover, in integrin $\alpha 3$-silenced cells anti-apoptotic protein $\mathrm{Bcl}-2$ was highly expressed, consistent with previous findings that $\mathrm{NF}-\kappa \mathrm{B}$ activation results in an increase in anti-apoptotic regulators such as Bcl-2, Bcl- $\mathrm{x}_{\mathrm{L}}, \mathrm{Bfl}-1 / \mathrm{A} 1$, and inhibitor of apoptosis $(13,26,27)$. We next examined the changes in activation of PI3K/Akt and ERK, which are key down-stream molecules of EGFR signaling pathways $(9,28)$. As shown in Fig. 4B, integrin $\alpha 3$-silenced cells showed little or no change in phosphorylation status of Akt as compared with control cells at the $24 \mathrm{~h}$ time point.

In contrast, activation of ERK in integrin $\alpha 3$-silenced cells was sustained up to $24 \mathrm{~h}$ in the absence or presence of mitogenic
A
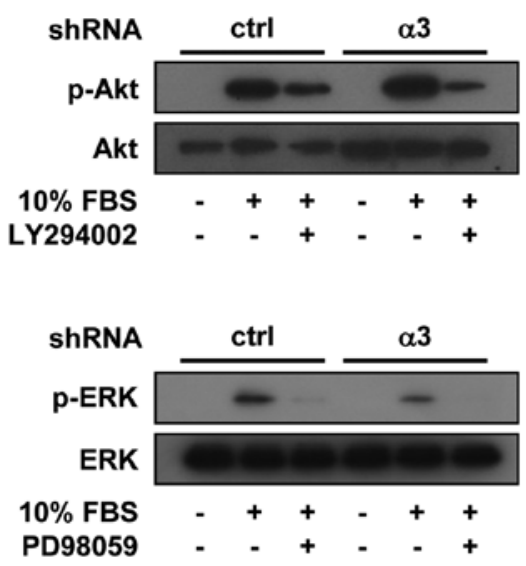

B

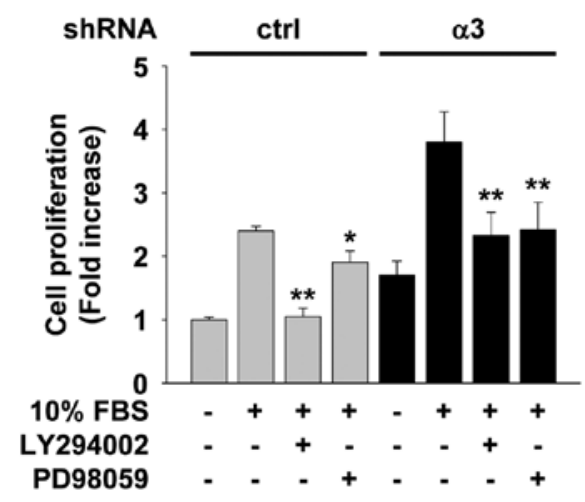

C

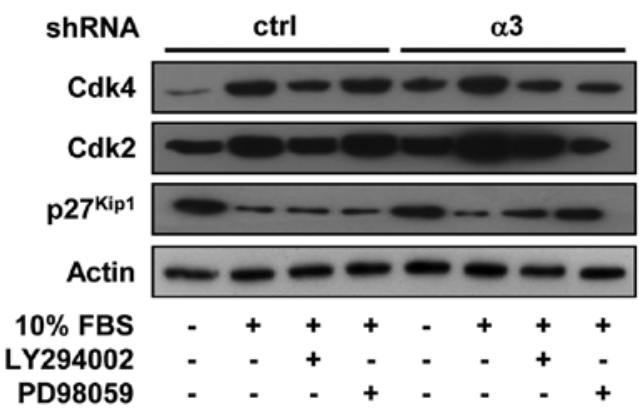

Figure 5. Effects of Akt and ERK signaling pathways on the expression of Cdks and proliferation in integrin $\alpha 3$-silenced cells. (A) Quiescent cells were pretreated with LY294002 $(10 \mu \mathrm{M})$ or PD98059 $(25 \mu \mathrm{M})$ for $30 \mathrm{~min}$, and then stimulated with $10 \%$ serum for $15 \mathrm{~min}$ (A) or $24 \mathrm{~h}$ (B and C). Cell proliferation and western blot analysis were performed as described in Materials and methods. Cell lysates were western-blotted with anti-phospho-Akt, anti-Akt, anti-phospho-ERK, anti-ERK, anti-Cdk4, anti-Cdk2, anti-p27 ${ }^{\mathrm{Kip} 1}$ or anti-actin antibodies. Results shown are representative of three independent experiments. Statistical significance is indicated $\left({ }^{*} \mathrm{p}<0.05,{ }^{* *} \mathrm{p}<0.01\right.$, compared with stimulated cells).

stimuli, indicating the cell mitogenesis and survival might be mediated through ERK rather than Akt activity. Pretreatment with PD98059, an inhibitor of ERK pathway or LY294002, an inhibitor of PI3K-Akt pathway, significantly inhibited the activation of ERK and Akt, and the proliferation of both control and integrin $\alpha 3$-silenced cells (Fig. 5A and B). Integrin $\alpha 3$-silenced cells are more responsive to PD98059 inhibition of cell proliferation as compared with control cells. Furthermore, 
A

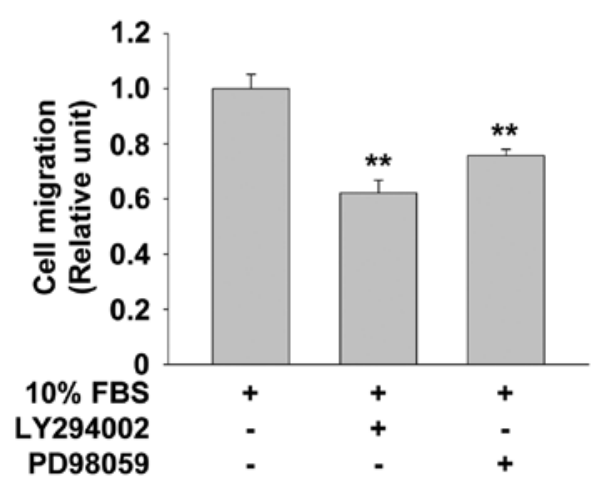

B

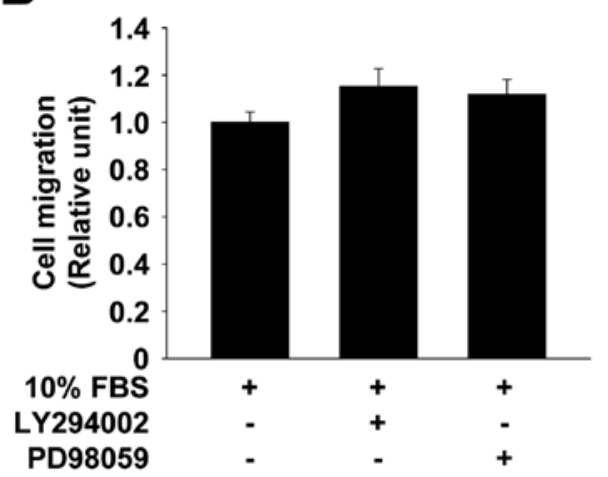

Figure 6. Enhanced migration of integrin $\alpha 3$-silenced cells is mediated by Akt- and ERK-independent mechanism. Quiescent control (A) and integrin $\alpha 3$-silenced (B) cells were pretreated with LY294002 (10 $\mu \mathrm{M})$ or PD98059 $(25 \mu \mathrm{M})$ for $30 \mathrm{~min}$, and then stimulated with $10 \%$ serum for $18 \mathrm{~h}$. Results from six independent experiments (mean $\pm \mathrm{SD}$ ) were represented as the percentage of maximally induced migration with $10 \%$ serum. Statistical significance is indicated $\left({ }^{* *} \mathrm{p}<0.01\right.$, compared with $10 \%$ serum-treated cells).

PD98059 treatment decreased the protein levels of both Cdk4 and Cdk2, and increased a Cdk inhibitor p27 $7^{\mathrm{Kip} 1}$ levels in integrin $\alpha 3$-silenced cells, but not in control cells (Fig. 5C), in a good agreement with our findings on cell proliferation (Fig. 5B). Finally, we examined the roles of Akt and ERK in integrin $\alpha 3$ silencing-induced cell migration. Pretreatment with LY294002 or PD98059 significantly reduced the migration of control cells (Fig. 6A). In contrast, in integrin $\alpha 3$-silenced cells neither LY294002 nor PD98059 treatment blocked cell migration (Fig. 6B). Taken together, these observations suggest that knockdown of integrin $\alpha 3$ expression in p53-deficient NSCLC cells induces cell proliferation through Akt- and ERK-dependent pathways, whereas enhanced cell migration is independent of the activation of Akt and ERK.

\section{Discussion}

In the present study we demonstrate that reduced expression of integrin $\alpha 3 \beta 1$ induces the proliferation and migration of p53-deficient NSCLC cells. In addition, we show that upregulation of EGFR, Cdks, NF-kB, and Bcl-2 and sustained activation of ERK in integrin $\alpha 3$-silenced cells are responsible for the accelerated cell mitogenesis and survival. Our study is the first demonstration that $\mathrm{p} 53$ functions to regulate integrin $\alpha 3 \beta 1$-EGFR-mediated signaling pathways and invasive phenotypes of NSCLC cells.

Integrin $\alpha 3 \beta 1$ is positively or negatively correlated with cancer invasion and metastasis $(6,29)$. Expression of integrin $\alpha 3 \beta 1$ is highly induced in the process of brain metastasis of NSCLC (30). In contrast, reduced expression of integrin $\alpha 3 \beta 1$ has been reported to be associated with the highly invasive and metastatic behavior of small cell lung cancer (7) and poor prognosis in patients with NSCLC (8). These conflicting observations may be due to heterogeneity of cancer types and stages as well as differences in cancer microenvironment.

Overexpressed, constitutively activated EGFR, and deregulation of EGFR signaling are closely related to highly aggressive behaviors and therapeutic resistance of lung cancers $(10,11)$, and these events are very complex. Increasing evidence indicates that cross-talk between integrin $\alpha 3 \beta 1$ and RTKs plays pivotal roles in angiogenesis and cancer progression $(4,31,32)$. Although potential roles of integrin $\alpha 3 \beta 1$ or EGFR in cancer progression have been reported, however, no relationship between integrin $\alpha 3 \beta 1$ and EGFR in regulating NSCLC cell proliferation and migration has been clearly investigated to date. A recent study demonstrates that integrin $\beta 1$ silencing inactivates the EGFR signaling pathways, resulting in suppression of tumorigenic properties of lung cancer cells (33). NF- $\kappa B$ has been reported to be activated by EGFR signaling events and positively associated with breast cancer cell proliferation and anti-apoptosis, indicating linkage between EGFR and $\mathrm{NF}-\mathrm{\kappa B}$ signaling (34). Mutations of the p53 tumor suppressor gene occur in a high percentage of lung cancer, resulting in cancer progression (35).

Our data show that integrin $\alpha 3$ silencing in p53-deficient H1299 cells induces the expression of EGFR and activation of ERK, and these events appear to be related to induction of Cdks, $\mathrm{NF}-\mathrm{KB}$, and Bcl-2, leading to cell proliferation and migration. These findings are correlated with a previous report that loss of p53 can drive NF-kB toward cancer-promoting activity by activation of signaling pathways including Akt and ERK, and induction of anti-apoptotic gene expression, leading to cancer growth, invasion and metastasis (12). In conclusion, our findings demonstrate that alterations in integrin $\alpha 3 \beta 1$ expression and subsequent signaling pathways may provide a molecular basis for the coordination of cell proliferation and migration in p53-deficient NSCLC, and suggest that expression of integrin $\alpha 3 \beta 1$ and regulation of EGFR-NF- $\kappa B$ signaling pathways result in suppression of invasive phenotypes of lung cancer.

\section{Acknowledgements}

This work was supported by Basic Science Research Program (2009-0065896) (2010-0021913) through the National Research Foundation of Korea (NRF) funded by the Ministry of Education, Science and Technology (MEST).

\section{References}

1. Cox D, Brennan M and Moran N: Integrins as therapeutic targets: lessons and opportunities. Nat Rev Drug Discov 9: 804-820, 2010.

2. Hood JD and Cheresh DA: Role of integrins in cell invasion and migration. Nat Rev Cancer 2: 91-100, 2002.

3. Hynes RO: Integrins: bidirectional, allosteric signaling machines. Cell 110: 673-687, 2002. 
4. Eliceiri BP: Integrin and growth factor receptor crosstalk. Circ Res 89: 1104-1110, 2001.

5. Desgrosellier JS and Cheresh DA: Integrins in cancer: biological implications and therapeutic opportunities. Nat Rev Cancer 10 9-22, 2010.

6. Kreidberg JA: Functions of $\alpha 3 \beta 1$ integrin. Curr Opin Cell Biol 12: 548-553, 2000

7. Barr LF, Campbell SE, Bochner BS and Dang CV: Association of the decreased expression of $\alpha 3 \beta 1$ integrin with the altered cell: environmental interactions and enhanced soft agar cloning ability of c-myc-overexpressing small cell lung cancer cells. Cancer Res 58: 5537-5545, 1998.

8. Adachi M, Taki T, Huang C, et al: Reduced integrin $\alpha 3$ expression as a factor of poor prognosis of patients with adenocarcinoma of the lung. J Clin Oncol 16: 1060-1067, 1998.

9. Lemmon MA and Schlessinger J: Cell signaling by receptor tyrosine kinases. Cell 141: 1117-1134, 2010.

10. Sharma SV, Bell DW, Settleman J and Haber DA: Epidermal growth factor receptor mutations in lung cancer. Nat Rev Cancer 7: $169-181,2007$

11. Hynes NE and Lane HA: ERBB receptors and cancer: the complexity of targeted inhibitors. Nat Rev Cancer 5: 341-354 2005.

12. Perkins ND: The diverse and complex roles of NF- $\kappa B$ subunits in cancer. Nat Rev Cancer 12: 121-132, 2012.

13. Kim YK, Lee EK, Kang JK, et al: Activation of NF-кB by HDAC inhibitor apicidin through Sp1-dependent de novo protein synthesis: its implication for resistance to apoptosis. Cell Death Differ 13: 2033-2041, 2006.

14. Cho Y-R, Choi S and Seo D-W: Sepiapterin regulates cell proliferation and migration: its association with integrin $\alpha 3 \beta 1$ and p53 in human lung cancer cells. Genes Genom 33: 577-582, 2011.

15. Seo D-W, Li H, Qu C-K, et al: Shp-1 mediates the antiproliferative activity of tissue inhibitor of metalloproteinase-2 in human microvascular endothelial cells. J Biol Chem 281: 3711-3721, 2006.

16. Kim S, Cho Y-R, Kim M-D, Kim H, Choi S and Seo D-W: Inhibitory effects of sepiapterin on vascular endothelial growth factor-A-induced proliferation and adhesion in human umbilical vein endothelial cells. Arch Pharm Res 34: 1571-1577, 2011.

17. Cho Y-R, Kim SH, Ko HY, Kim M-D, Choi SW and Seo D-W Sepiapterin inhibits cell proliferation and migration of ovarian cancer cells via down-regulation of $\mathrm{p} 70^{\mathrm{S} 6 \mathrm{~K}}$-dependent VEGFR-2 expression. Oncol Rep 26: 861-867, 2011.

18. Seo D-W, Kim SH, Eom S-H, et al: TIMP-2 disrupts FGF-2induced downstream signaling pathways. Microvasc Res 76: 145-151, 2008.

19. Hong SY, Cho JY and Seo D-W: Ginsenoside Rp1 inhibits proliferation and migration of human lung cancer cells. Biomol Ther 19: 411-418, 2011
20. Hodivala-Dilke KM, DiPersio CM, Kreidberg JA and Hynes RO Novel roles for $\alpha 3 \beta 1$ integrin as a regulator of cytoskeletal assembly and as a trans-dominant inhibitor of integrin receptor function in mouse keratinocytes. J Cell Biol 142: 1357-1369, 1998.

21. Gogali A, Charalabopoulos K and Constantopoulos S: Integrin receptors in primary lung cancer. Exp Oncol 26: 106-110, 2004.

22. Sherr CJ: The Pezcoller lecture: cancer cell cycles revisited. Cancer Res 60: 3689-3695, 2000.

23. Mayo MW, Denlinger CE, Broad RM, et al: Ineffectiveness of histone deacetylase inhibitors to induce apoptosis involves the transcriptional activation of NF- $\kappa \mathrm{B}$ through the Akt pathway. J Biol Chem 278: 18980-18989, 2003.

24. Stetler-Stevenson WG and Seo D-W: TIMP-2: an endogenous inhibitor of angiogenesis. Trends Mol Med 11: 97-103, 2005.

25. DiPersio CM, Shao M, Di Costanzo L, Kreidberg JA and Hynes RO: Mouse keratinocytes immortalized with large T antigen acquire $\alpha 3 \beta 1$ integrin-dependent secretion of MMP-9/ gelatinase B. J Cell Sci 113: 2909-2921, 2000

26. Heckman C, Mehew J and Boxer L: NF- $\kappa$ B activates Bcl-2 expression in $\mathrm{t}(14 ; 18)$ lymphoma cells. Oncogene 21 : 3898-3908, 2002.

27. Lee HH, Dadgostar H, Cheng Q, Shu J and Cheng G: NF- $\kappa$ Bmediated up-regulation of $\mathrm{Bcl}-\mathrm{x}$ and $\mathrm{Bfl}-1 / \mathrm{A} 1$ is required for CD40 survival signaling in B lymphocytes. Proc Natl Acad Sci USA 96: 9136-9141, 1999.

28. Hanahan D and Weinberg RA: Hallmarks of cancer: the next generation. Cell 144: 646-674, 2011.

29. Stipp CS: Laminin-binding integrins and their tetraspanin partners as potential antimetastatic targets. Expert Rev Mol Med 12: e3, 2010

30. Yoshimasu T, Sakurai T, Oura S, et al: Increased expression of integrin $\alpha 3 \beta 1$ in highly brain metastatic subclone of a human non-small cell lung cancer cell line. Cancer Sci 95: 142-148, 2004.

31. Seo D-W, Li H, Guedez L, et al: TIMP-2 mediated inhibition of angiogenesis: an MMP-independent mechanism. Cell 114: 171-180, 2003.

32. Seo D-W, Saxinger WC, Guedez L, Cantelmo AR, Albini A and Stetler-Stevenson WG: An integrin-binding N-terminal peptide region of TIMP-2 retains potent angio-inhibitory and antitumorigenic activity in vivo. Peptides 32: 1840-1848, 2011.

33. Morello V, Cabodi S, Sigismund S, et al: $\beta 1$ integrin controls EGFR signaling and tumorigenic properties of lung cancer cells. Oncogene 30: 4087-4096, 2011.

34. Biswas DK and Iglehart JD: Linkage between EGFR family receptors and nuclear factor kappaB (NF- $\kappa \mathrm{B})$ signaling in breast cancer. J Cell Physiol 209: 645-652, 2006.

35. Fuster JJ, Sanz-González SM, Moll UM and Andrés V: Classic and novel roles of $\mathrm{p} 53$ : prospects for anticancer therapy. Trends Mol Med 13: 192-199, 2007. 